\title{
A comparison of coronary angiography and myocardial perfusion studies, using quantitative scoring systems
}

Preesha Premsagar", Colleen Aldous" and Tonya Esterhuizent

*Department of Internal Medicine, Nelson R Mandela School of Medicine, University of KwaZulu-Natal, Durban, South Africa "Department of Clinical Medicine, Nelson R Mandela School of Medicine, University of KwaZulu-Natal, Durban, South Africa tDivision of Epidemiology/Biostatistics, Department of Global Health, Faculty of Medical and Health Sciences, Stellenbosch University and Tygerberg Hospital, Bellville, South Africa

Address for correspondence:

Dr Preesha Premsagar

Department of Internal Medicine

Nelson R Mandela School of Medicine

University of KwaZulu-Natal

Durban

4001

South Africa

Email:

preeshal@yahoo.com

\section{INTRODUCTION}

Myocardial perfusion studies are often performed on patients with suspected coronary artery disease (CAD) to non-invasively evaluate left ventricular function and coronary blood supply, and identify the high risk patient needing angiography. (I) Outcomes from the 2 studies may sometimes differ in patients on whose the tests were conducted correctly according to protocol. The need to identify the cause of the observed difference arises. While research conducted to evaluate the difference is extensive, there is however little research to quantitatively compare the 2 studies using an unbiased numerical system.

The Synergy between Percutaneous Coronary Intervention with Taxus and Cardiac Surgery (SYNTAX) score, developed from the SYNTAX trial, characterise coronary anatomy based on 9 anatomic criteria. Following this trial, the European Society of Cardiology and The Japanese Circulation Society had produced guidelines forming an integral part in the decision making for coronary revascularisation. ${ }^{(2,3)}$ The summed difference score (SDS) measures the level of ischaemia on myocardial perfusion using a 17 segment model.(4,5,6) Our study aimed to evaluate the relationship between nuclear myocardial perfusion

\section{ABSTRACT}

Background: Results of myocardial perfusion for screening coronary artery disease (CAD), and angiography for diagnosing CAD, can be quantified using summed difference score (SDS) and Synergy between Percutaneous Coronary Intervention with Taxus and Cardiac Surgery (SYNTAX) score, respectively.

Aim: The aim is to quantitatively compare myocardial perfusion studies with angiography amongst South African patients using scoring systems.

Methods: SDS on myocardial perfusion and SYNTAX score on angiography were compared. Regional scores within each vessel (left anterior descending (LAD), circumflex and right coronary artery (RCA)) were also compared. Scores were further risk categorised and evaluated.

Results: The weak correlation between SDS and SYNTAX score $(r s=0.210, p=0.015)$, became slightly negative when SYNTAX scores were stratified into low and intermediate-high risk groups. Regionally, LAD had very slight positive correlation $(r s=0.171, p=0.048)$, circumflex ( $r s=0.164, p=0.058)$, and RCA $(r s=0.116$, $\mathrm{p}=\mathbf{0 . 1 8 4 )}$ no correlation. Conversely, comparison of scores categories was significant $(p=0.00 I)$.

Conclusions: Inherent differences in the design of $\mathbf{2}$ scoring systems that evaluate the LAD territory may explain these findings. These differences were dominance, regional blood flow distribution and significant luminal diameter reduction. This study highlights the need to interpret myocardial perfusion results contextually during CAD screening. SAHeart 2021;18:108-1।6

imaging and coronary angiography amongst South African participants, using these quantitative scoring systems to help explain the different investigation outcomes. Our research has only found one other study that performed this evaluation; in Japan Tanaka evaluated the total SYNTAX score and total SDS score.(7)

\section{METHOD}

\section{Patient selection}

We studied patients who did not have typical angina but CAD was suspected in them based on demographic information, medical comorbid risks, electrocardiographic (ECG) findings. 
These patients therefore needed to be screened for CAD noninvasively, and were subsequently referred from the satellite hospitals to Inkosi Albert Luthuli Central Hospital, Durban, South Africa cardiology from January 2002 - December 2008. Patients with known CAD were excluded from the study. From the patients at IALCH who underwent myocardial perfusion studies, only those who achieved $80 \%$ of target heart rate on the stress part of sestaMIBI and also underwent angiography within six month and were included in the study. Target heart rate was defined as (220-age in years) beats per minute for women and (200-age in years) beats per minute for men. Beta blockade is discontinued for the duration of the stress part of the myocardial perfusion study. For patients selected by these criteria, screening was an essential step to angiography; and quantitative scores were able to be determined accurately on 80\% THR. Written informed consent for investigation was obtained from patients for the investigations to be performed. The study was approved by the Biomedical Research Ethics Committee (BREC) of University of KwaZulu-Natal Nelson R Mandela School of Medicine. There was no conflict of interest.

\section{Myocardial perfusion and SDS}

SestaMIBI (methoxyisobutylisonitrile) myocardial perfusion was a 2-day imaging protocol (stress-rest) using a gamma camera to measure cardiac uptake of $15 \mathrm{mCi}$ of technetium $99 \mathrm{~m}$ - sestamibi. On the first day, Bruce Protocol treadmill testing was performed and technetium was injected at peak exercise to $80 \%$ of target heart rate (THR). Single photon emission computerised tomography (SPECT) imaging with gated acquisition was performed. Images were analysed with MPI Siemens Corridor 4DM V50I. The technetium 99m-sestamibi dose was repeated for rest imaging study 24 - 72 hours later. ${ }^{(4,5)}$ The heart was examined in the 17-segment model. SPECT imaging defines and orientates the heart at $90^{\circ}$ to the long axis of the left ventricle, slicing through the cardiac apex and the centre of the mitral valve. Cardiac planes are named short axis, vertical long axis, and horizontal long axis. The gamma camera imaged the heart along the short axis into the apex, apical layer, mid layer and basal layer, which consisted of 1, 4, 6, and 6 segments, respectively, applying the standard 17-segment model (Figure IA). The coronary artery territories (LAD, circumflex, $\mathrm{RCA}$ ) corresponding to the segment through the slices have been derived ${ }^{(6)}$ (Figure IB, Table I).

The perfusion in each segment of the model during the stress study was assigned a summed stress score (SSS) on a 5 point scale. The total of all 17 segments indicated the semi-quantitative ischaemic burden. The rest study assigned the summed rest score (SRS) represented the extent and severity of infarction. The result of the rest-stress images, which is the summed

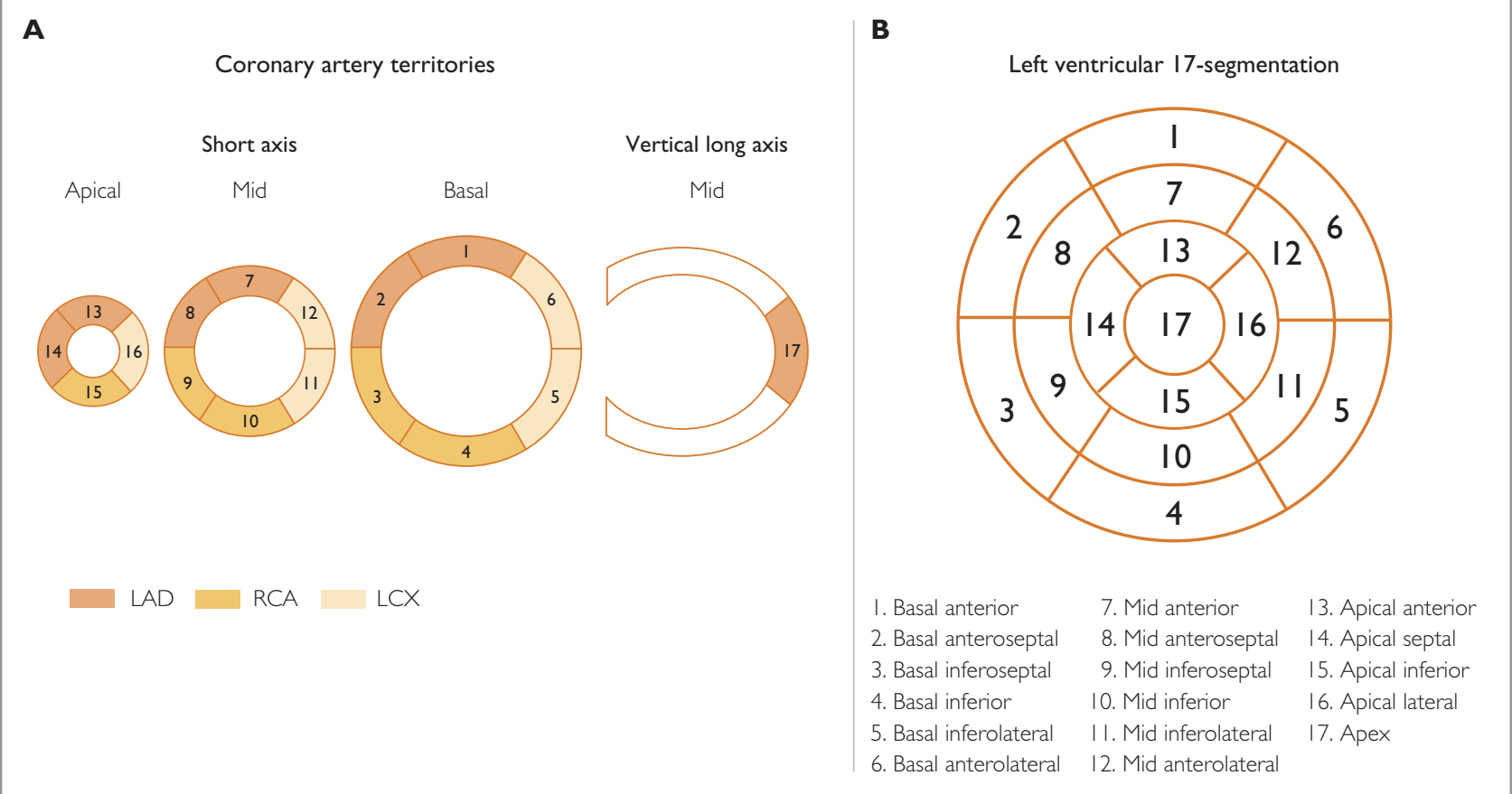

FIGURE I: Myocardial perfusion model for SDS scoring. 
TABLE I: Scoring systems and regional divisions.

\section{SDS and SYNTAX scores}

\begin{tabular}{|c|c|c|c|}
\hline \multicolumn{2}{|r|}{5 point scale } & \multicolumn{2}{|c|}{ Total SSS for 17 segments and indication } \\
\hline 0 & Normal tracer uptake & $<2$ & Normal \\
\hline । & Mildly abnormal (slight reduction in tracer uptake/equivocal) & $2-4$ & Mildly abnormal \\
\hline 2 & Moderately abnormal (moderate reduction tracer uptake/equivocal) & $5-8$ & Moderately abnormal \\
\hline 3 & Severely abnormal (severe reduction in tracer uptake/equivocal) & $>8$ & Severely abnormal \\
\hline 4 & Absence of tracer uptake & & \\
\hline & SDS & \multicolumn{2}{|c|}{ Corresponding ischaemic burden quantity } \\
\hline & $1-3$ & \multicolumn{2}{|l|}{ Normal } \\
\hline & $4-8$ & \multicolumn{2}{|l|}{ Mildly abnormal } \\
\hline & $9-13$ & \multicolumn{2}{|c|}{ Moderately abnormal } \\
\hline & $>13$ & \multicolumn{2}{|c|}{ Severely abnormal/infarct } \\
\hline
\end{tabular}

Angiography, SYNTAX Score, SYNTAX Risk Category

\begin{tabular}{|c|c|c|c|c|c|c|}
\hline \multicolumn{4}{|c|}{ Segment weighing factors for arterial tree for dominant sides } & \multirow{2}{*}{\multicolumn{3}{|c|}{ Points allocated to the lesion }} \\
\hline $\begin{array}{l}\text { Segment } \\
\text { number }\end{array}$ & Vessel segment & Right dominant & Left dominant & & & \\
\hline 1 & RCA proximal & I & 0 & \multirow[b]{2}{*}{ Diameter reduction } & Total occlusion & $\times 5$ \\
\hline 2 & RCA mild & 1 & 0 & & $\begin{array}{l}\text { Significant } \\
(50 \%-99 \%)\end{array}$ & $\times 2$ \\
\hline 3 & RCA distal & I & 0 & \multirow{6}{*}{ Total occlusion } & $\begin{array}{l}\text { Age }>3 \text { months/ } \\
\text { unknown }\end{array}$ & +1 \\
\hline 4 & Posterior descending artery & I & $\mathrm{n} / \mathrm{a}$ & & Blunt stump & +1 \\
\hline 16 & Posterolateral branch from RCA & 0.5 & $\mathrm{n} / \mathrm{a}$ & & Bridging & +1 \\
\hline $16 \mathrm{a}$ & Posterolateral branch from RCA & 0.5 & $\mathrm{n} / \mathrm{a}$ & & $\begin{array}{l}\text { Ist segment visible } \\
\text { beyond } \mathrm{T} / \mathrm{O}\end{array}$ & +1 \\
\hline $16 b$ & Posterolateral branch from RCA & 0.5 & $\mathrm{n} / \mathrm{a}$ & & $\begin{array}{l}\text { Side branch } \\
<1.5 \mathrm{~mm}\end{array}$ & +1 \\
\hline $16 c$ & Posterolateral branch from RCA & 0.5 & $\mathrm{n} / \mathrm{a}$ & & $\begin{array}{l}\text { Side branch } \\
>1.5 \mathrm{~mm}\end{array}$ & +1 \\
\hline 5 & Left main & 5 & 6 & \multirow{4}{*}{ Trifurcations } & I disease segment & +3 \\
\hline 6 & LAD proximal & 3.5 & 3.5 & & $\begin{array}{l}2 \text { diseased } \\
\text { segments }\end{array}$ & +4 \\
\hline 7 & LAD mid & 2.5 & 2.5 & & $\begin{array}{l}3 \text { diseased } \\
\text { segments }\end{array}$ & +5 \\
\hline 8 & LAD apical & 1 & I & & $\begin{array}{l}4 \text { diseased } \\
\text { segments }\end{array}$ & +6 \\
\hline 9 & First diagonal & 1 & 1 & \multirow{3}{*}{ Bifurcations } & Type A, B, C & +1 \\
\hline $9 a$ & First diagonal a & 1 & 1 & & Type D, E, F, G & +2 \\
\hline 10 & Second diagonal & 0.5 & 0.5 & & Angulation $<70^{\circ}$ & +1 \\
\hline $10 \mathrm{a}$ & Second diagonal a & 0.5 & 0.5 & \multirow{6}{*}{ Others } & Aorto-osteal & +1 \\
\hline 11 & Proximal circumflex artery & 1.5 & 2.5 & & Severe tortuosity & +2 \\
\hline 12 & $\begin{array}{l}\text { Intermediate/anterolateral } \\
\text { artery }\end{array}$ & 1 & I & & Length $>20 \mathrm{~mm}$ & +1 \\
\hline $12 \mathrm{a}$ & Obtuse marginal a & 1 & 1 & & Heavy calcification & +2 \\
\hline $12 b$ & Obtuse marginal $b$ & 1 & 1 & & Thrombus & +1 \\
\hline 13 & Distal circumflex artery & 0.5 & 1.5 & & Diffuse disease & +1 \\
\hline 14 & Left posterolateral & 0.5 & 1 & \multicolumn{3}{|c|}{ SYNTAX Risk Category (\%MACE risk in 12 months) } \\
\hline $14 a$ & Left posterolateral a & 0.5 & I & Low $\leq 22$ & c & $\begin{array}{l}\text { CABG arm } \\
=14.7 \%\end{array}$ \\
\hline $14 b$ & Left posterolateral b & 0.5 & I & Intermediate 23-32 & $\mathrm{PCl}$ arm $=16.7 \%$ & $\begin{array}{l}\text { CABG arm } \\
=12.0 \%\end{array}$ \\
\hline 15 & Posterior descending & $\mathrm{n} / \mathrm{a}$ & I & High $\geq 33$ & $\mathrm{PCl}$ arm $=23.4 \%$ & $\begin{array}{l}\text { CABG arm } \\
=10.9 \%\end{array}$ \\
\hline
\end{tabular}

$L A D=$ left anterior descending, LMS = Left main stem, RCA = right coronary artery, SDS = summed difference score, SYNTAX = synergy between percutaneous coronary intervention with taxus and cardiac surgery. 
TABLE I: Scoring systems and regional divisions continued.

\begin{tabular}{|c|c|c|}
\hline \multicolumn{3}{|c|}{ Arterial corresponding arteries of regional SYNTAX score and regional SDS segment } \\
\hline Artery & SYNTAX on Angiography & SDS on myocardial perfusion (muscle territory \\
\hline $\begin{array}{l}\text { Left anterior descending artery } \\
\qquad(\mathrm{LAD})\end{array}$ & $\begin{array}{l}\text { 5. LMS } \\
\text { 6. Proximal LAD } \\
\text { 7. Mid LAD } \\
\text { 8. Apical LAD } \\
\text { 9. First Diagonal } \\
\text { 9a. Additional First Diagonal } \\
\text { 10. Second Diagonal } \\
\text { 10a. Additional Second Diagonal } \\
\text { 1।. Ramus }\end{array}$ & $\begin{array}{c}\text { Basal Anterior } \\
\text { Basal Anteroseptal } \\
\text { Mid Anterior } \\
\text { Mid Anteroseptal } \\
\text { Apical Anterior } \\
\text { Apical Septal } \\
\text { Apex }\end{array}$ \\
\hline Circumflex & $\begin{array}{l}\text { 12. Proximal circumflex } \\
\text { 12a. First Obtuse Marginal } \\
\text { 12b. Second Obtuse Marginal } \\
\text { 13. Distal circumflex } \\
\text { 14. Left Posterolateral } \\
\text { 14a. First Left Posterolateral } \\
\text { 14b. Second Left Posterolateral } \\
\text { 15. Posterior Descending Artery (Left Dom) }\end{array}$ & $\begin{array}{c}\text { Basal Inferolateral } \\
\text { Basal Anterolateral } \\
\text { Mid Inferolateral } \\
\text { Mid Anterolateral } \\
\text { Apical Lateral }\end{array}$ \\
\hline Right coronary artery (RCA) & $\begin{array}{l}\text { 1. Proximal RCA } \\
\text { 2. Mid RCA } \\
\text { 3. Distal RCA } \\
\text { 4. Posterior Descending Artery } \\
\text { 5. Posterior Lateral branch Of RCA } \\
\text { 16a. Ist Post Lateral branch of RCA } \\
\text { 16b. 2nd Post Lateral branch of RCA } \\
\text { 16c. 3rd Post Lateral branch of RCA }\end{array}$ & $\begin{array}{l}\text { Basal Inferoseptal } \\
\text { Basal Inferior } \\
\text { Mid Inferoseptal } \\
\text { Mid Inferior } \\
\text { Apical Inferior }\end{array}$ \\
\hline
\end{tabular}

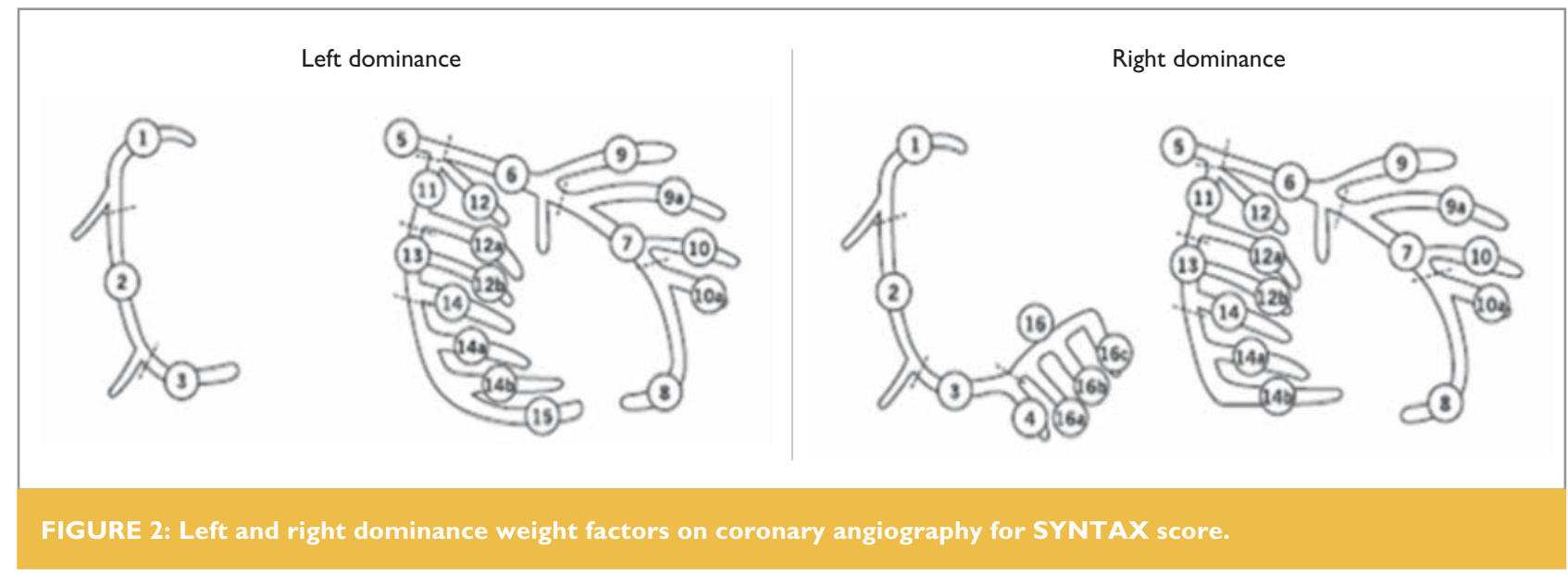

difference score (SDS), was determined using the equation: SSS-SRS=SDS. The SDS indicated the ischaemic burden present. The score was divided into 4 categories of ischaemic burden: normal, mildly abnormal, moderately abnormal or severely abnormal (or myocardial infarct). ${ }^{(4,5,6)}$ The study was interpreted as normal if no perfusion defects were detected and as abnormal if evidence of ischaemia, infarction, or a combination is present (Table I). The ejection fraction on stress and rest tests was also documented. Studies were reported on by the Departments of Nuclear Medicine and Cardiology at Albert Luthuli Hospital.
Angiography and SYNTAX score

Angiography was reported as normal if vessels had no atheroma or non-occlusive atheroma, and abnormal if single, double or triple vessel disease with $>50 \%$ luminal stenosis was detected. Angiography was scored with the SYNTAX score, calculated using 2 factors: the segment weighing factors and the lesions adverse characteristics. The coronary arteries were divided into 16 segments representing the coronary tree ${ }^{(8)}$ (Table I). Left and right dominance had different trees. In the right dominated system, the RCA and LMS supply 16\% and $84 \%$ of the blood to the left ventricle, respectively. From the $84 \%$, two thirds and 
one third flowed through the LAD and circumflex, respectively. In the left dominated system, there was no RCA supply; therefore the LMS supply was 100\%, and the RCA share of blood to the LV was through the circumflex. A weighting factor was given for each segment of the vessel, representing the portion of blood supply through each vessel to the LV for the left or right dominant system of normal coronary vessels (Figure 2). ${ }^{(8)}$

The degree of stenosis and the other adverse characteristics were visually assessed on angiography. A lesion above 50\% stenosis was considered significant. A subtotal stenosis (50\% 99\%) and total occlusions (100\%) were assigned a diameter reduction value of 2 and 5 , respectively. The weighing factor for each vessel in the arterial tree was multiplied by the appropriate diameter reduction value. The points were then added for all the tree segments. Further points were added for other adverse characteristics. The total was the SYNTAX score. The total SYNTAX score was assigned to a risk category. A score from $\leq 22$ was low risk, 23 - 32 was intermediate risk, and $\geq 33$ was high risk. ${ }^{(2,3)}$ The online calculator was used for the measurement key, available at http://www.syntaxscore.com (Table I). The LV function category was also captured.

\section{Regional SDS and SYNTAX scores}

The regional SYNTAX scores were calculated for each artery ( $L A D$, circumflex, RCA), which added up to the total SYNTAX score. The regional SDS was calculated for each arterial territory (LAD segments, circumflex segments, RCA segments) which added up to the total SDS. For arteries, the regional SYNTAX score was paired with the corresponding regional SDS segments (Table I).

\section{Statistical analysis}

The study data was analysed with the Statistical Package for Social Science (SPSS) version 25.0. Descriptive tests were done to evaluate the demographics, SDS and SYNTAX scores. Chi squared tests were used to analyse the overall normal and abnormal outcomes on myocardial perfusion and angiography. Spearman's correlation analysis was used to assess the relationship between the scoring systems due to non-normal distribution of the quantitative data. ANOVA (analysis of variance) tests were used to compare the percentage stress and rest EF on myocardial perfusion between LV function categories.

\section{RESULTS}

Demographics and risk factors

From 2002 - 2008, there were 525 patients who did not have typical angina referred from the satellite hospitals to IALCH cardiology, for non-invasive screening for $C A D$, and possible angiography. Of the 525, there were 173 who underwent angiography. Of these 173, only 134 achieved $80 \%$ of target heart rate. The cohort therefore consisted of 134 participants. Descriptive statistics for demographics and CAD risk factors are shown below (Table II).

Normal and abnormal results for myocardial perfusion and angiography

Myocardial perfusion studies were used for CAD screening and coronary angiography was used as the gold standard CAD diagnosis. On cross-tabulation of normal and abnormal results for myocardial perfusion studies and angiography, there was no significant association $(p=0.127)$. Myocardial perfusion had a sensitivity of $72.5 \%$ and specificity of $40.0 \%$ compared with angiography. On angiography, 103 (76\%) participants were right side dominant, 25 (19\%) participants were left side dominant, and 6 (5\%) participants were co-dominant (Table III).

\section{Evaluation of scoring systems}

The total SDS and total SYNTAX scores were calculated for the myocardial perfusion studies and angiograms. The regional scores for $L A D$, circumflex and RCA were also calculated. There was a weak positive correlation between the total SYNTAX score and total SDS ( $r s=0.210, p=0.015)$. LAD had

TABLE II: Descriptive statistics for demographics and medical comorbidities $(n=\mid 34)$.

\begin{tabular}{|c|c|c|c|c|c|c|c|}
\hline \multirow{2}{*}{ Age } & Minimum & Maximum & Range & Mean & Std Error & Std Dev & Variance \\
\hline & 28 & 71 & 43 & 51.51 & 0.820 & 9.491 & 90.086 \\
\hline \multirow{2}{*}{ Race } & Black & Coloured & White & Indian & \multirow{2}{*}{\multicolumn{3}{|c|}{$134(100 \%)$}} \\
\hline & $6(4.5 \%)$ & $6(4.5 \%)$ & 20 (14.9\%) & $102(76.1 \%)$ & & & \\
\hline \multirow{2}{*}{ Gender } & \multicolumn{2}{|c|}{ Female } & \multicolumn{2}{|c|}{ Male } & \multicolumn{3}{|c|}{ Total } \\
\hline & \multicolumn{2}{|c|}{68 (50.7\%) } & \multicolumn{2}{|c|}{66 (49.3\%) } & \multicolumn{3}{|c|}{$134(100 \%)$} \\
\hline \multirow{2}{*}{$\begin{array}{l}C A D \text { risk } \\
\text { factors }\end{array}$} & Diabetes & Hypertension & Dyslipidaemia & Smoking & Family History & Increased WC & BMI $25 \mathrm{~kg} / \mathrm{m}^{2}$ \\
\hline & $65(36 \%)$ & 116 (67\%) & 116 (67\%) & $80(47 \%)$ & $94(54 \%)$ & 55 (32\%) & 132 (76\%) \\
\hline
\end{tabular}




\begin{tabular}{|c|c|c|c|c|}
\hline \multicolumn{5}{|c|}{ Angiography } \\
\hline Abnormal angiograms & \multicolumn{3}{|c|}{ Single vessel disease $=28$, double vessel disease $=17$, triple vessel disease $=27$} & $=69$ \\
\hline Normal angiograms & \multicolumn{3}{|c|}{ No atheroma $=37$, non-occlusive atheroma $=28$} & $=65$ \\
\hline \multicolumn{5}{|c|}{ Cross-tabulation of myocardial perfusion studies and angiogram results } \\
\hline & \multicolumn{2}{|c|}{ Angiograms } & Total & Chi square \\
\hline \multirow{2}{*}{ Myocardial perfusion studies } & $\begin{array}{l}\text { Abnormal angiogram, } \\
\text { abnormal perfusion } \\
\text { (a) }=50\end{array}$ & $\begin{array}{l}\text { Normal angiogram, } \\
\text { abnormal perfusion } \\
\text { (b) }=39\end{array}$ & 89 & \multirow{2}{*}{$p=0.127$} \\
\hline & $\begin{array}{l}\text { Abnormal angiogram, } \\
\text { normal perfusion } \\
\text { (c) }=19\end{array}$ & $\begin{array}{c}\text { Normal angiogram, normal } \\
\text { perfusion } \\
\text { (d) }=26\end{array}$ & 45 & \\
\hline Total & 69 & 65 & 134 & \\
\hline \multicolumn{5}{|c|}{ Binary testing } \\
\hline Test & \multicolumn{2}{|c|}{ Equation } & Result & $95 \%$ confidence intervals \\
\hline Sensitivity & \multicolumn{2}{|c|}{$a /(a+c) \times 100$} & $72.5 \%$ & $(0.60,0.82)$ \\
\hline Specificity & \multicolumn{2}{|c|}{$d /(d+b) \times 100$} & $40.0 \%$ & $(0.28,0.53)$ \\
\hline $\begin{array}{l}\text { Negative predictive value } \\
\text { (NPV) }\end{array}$ & \multicolumn{2}{|c|}{$d /(d+c) \times 100$} & $57.8 \%$ & $(0.45,0.67)$ \\
\hline $\begin{array}{l}\text { Positive predictive value } \\
\text { (PPV) }\end{array}$ & \multicolumn{2}{|c|}{$a /(a+b) \times 100$} & $56.2 \%$ & $(0.42,0.72)$ \\
\hline
\end{tabular}

evidence of a very weak positive correlation between SYNTAX scores and SDS ( $r s=0.171, p=0.048)$. Circumflex ( $r s=0.164$, $p=0.058$ ) and RCA ( $r s=0.116, p=0.184$ ) had no correlation between SYNTAX score and SDS (Table IV).

\section{Ischaemic burden category and SYNTAX risk category}

The total SDS for the cohort were categorised into the ischaemic burden category. The total SYNTAX scores for the cohort were categorised into the coronary risk category. These categories were assessed for association between ischaemic burden and coronary risk. There was evidence of an association when the intermediate and high risk categories were grouped together and compared with the low risk category for ischaemic burden $(p=0.00 \mathrm{I})$. This was observed in the low risk group, and diminished in the intermediate-high group (Table IV).

To further assess the correlation between SYNTAX scores and SDS, the SYNTAX score was stratified into $\leq 22$ (low risk) and $>22$ (intermediate-high risk). Results from the split strata showed that the correlation disappeared in each stratum and actually became slightly negative in the $>22$ group (Table IV).

\section{Left ventricular contractility}

The LV contractility was evaluated using the EF percentage on myocardial perfusion and using the LV function category on angiogram. There was a strong positive linear correlation between rest and stress \%EF on myocardial perfusion $(R=0.928$. $p<0.00$ I) (Figure 3). The LV function on angiogram was categorised in one 5 of categories; these were good, mildly impaired, moderately impaired, severely impaired and overall hypo-contractile. The mean \%EF on the stress and rest tests were compared between the categories of LVF on the angiogram using analysis of variance (ANOVA) test. The myocardial perfusion \%EF's were significantly different between the categories of LVF overall ( $p=0.014$ for \%stress EF and $p=0.015$ for \%rest EF). Post hoc testing with Bonferroni adjustment for multiple comparisons was performed. It determined that the differences were between good LVF and moderately impaired LVF for the \%stress EF ( $p=0.012$, 95\% confidence interval lower bound 2.268I, upper bound 29.9786) and between mildly impaired LVF and overall hypo-contractile for \%rest EF $(p=0.012,95 \%$ confidence interval lower bound -29.9786 , upper bound -2.2681 ).

\section{DISCUSSION}

Myocardial perfusion is a screening tool to identify patients for angiography and possible revascularisation. A comparison between the overall normal and abnormal outcomes on myocardial perfusion and angiography amongst 134 participants with suspected CAD, showed no association. The sensitivity was $72.5 \%$ and specificity only $40.0 \%$. The 19 participants with normal myocardial perfusion studies and abnormal angiography, may have an excellent collateral blood supply to the ischaemic 
TABLE IV: Evaluation of myocardial perfusion and angiography, using SDS and SYNTAX scores, and ischaemic burden category and SYNTAX risk category.

\begin{tabular}{|c|c|c|c|c|c|c|c|c|}
\hline \multicolumn{9}{|c|}{ Evaluation of SDS (myocardial perfusion) and SYNTAX scores (angiography) } \\
\hline \multirow[t]{2}{*}{ Score } & Range & Min & Max & Mean & Median & Std. Error & Std. Dev & Variance \\
\hline & 40 & 0 & 40 & 7.9 & 5.00 & 0.787 & 9.109 & 82.978 \\
\hline Regional SDS for LAD & 18 & 0 & 18 & 2.89 & 0 & 0.347 & 4.014 & 16.115 \\
\hline $\begin{array}{l}\text { Regional SDS for } \\
\text { circumflex }\end{array}$ & 10 & 0 & 10 & 1.69 & 0 & 0.239 & 2.765 & 7.645 \\
\hline Regional SDS for RCA & 17 & 0 & 17 & 3.50 & 2 & 0.381 & 4.409 & 19.440 \\
\hline Total SYNTAX score & 40.0 & 0.0 & 40.0 & 7.0 & 2.00 & 0.839 & 9.712 & 95.102 \\
\hline $\begin{array}{l}\text { Regional SYNTAX score } \\
\text { for LAD }\end{array}$ & 37.5 & 0.0 & 37.5 & 4.7 & 0.0 & 0.718 & 8.309 & 69.032 \\
\hline $\begin{array}{l}\text { Regional SYNTAX score } \\
\text { for circumflex }\end{array}$ & 13.0 & 0.0 & 13.0 & 1.0 & 0.0 & 0.201 & 2.330 & 5.434 \\
\hline $\begin{array}{l}\text { Regional SYNTAX score } \\
\text { for RCA }\end{array}$ & 15.0 & 0.0 & 15.0 & 1.3 & 0.0 & 0.253 & 2.940 & 8.644 \\
\hline \multicolumn{9}{|c|}{ Correlation between total SDS on myocardial perfusion and total SYNTAX score on angiography $(n=134)$} \\
\hline \multicolumn{9}{|c|}{ Correlation of SDS and SYNTAX score using Spearman's Rho } \\
\hline \multicolumn{3}{|c|}{ SDS on myocardial perfusion } & \multicolumn{3}{|c|}{ SYNTAX score on Angiography } & \multicolumn{2}{|c|}{$\begin{array}{l}\text { Spearman's Correlation } \\
\text { Coefficient }\left(r_{s}\right)\end{array}$} & $\begin{array}{l}\text { P value } \\
\text { (2-tailed) }\end{array}$ \\
\hline \multicolumn{3}{|c|}{ Total SDS on myocardial perfusion } & \multicolumn{3}{|c|}{ Total SYNTAX score on angiogram } & \multicolumn{2}{|c|}{0.210} & 0.210 \\
\hline \multicolumn{3}{|c|}{ SDS for LAD only } & \multicolumn{3}{|c|}{ SYNTAX score for LAD only } & \multicolumn{2}{|c|}{0.171} & 0.171 \\
\hline \multicolumn{3}{|c|}{ SDS for circumflex only } & \multicolumn{3}{|c|}{ SYNTAX score for circumflex only } & \multicolumn{2}{|c|}{0.164} & 0.164 \\
\hline \multicolumn{3}{|c|}{ SDS for RCA only } & \multicolumn{3}{|c|}{ SYNTAX score for RCA only } & \multicolumn{2}{|c|}{0.116} & 0.116 \\
\hline \multicolumn{9}{|c|}{ Ischaemic burden category and SYNTAX risk category } \\
\hline \multicolumn{9}{|c|}{ Cross tabulation between risk categories } \\
\hline & & & & \multicolumn{5}{|c|}{ SDS ischaemic burden category } \\
\hline & & & & Vone $(1-3)$ & Mild $(4-8)$ & $\begin{array}{l}\text { Moderate } \\
(9-13)\end{array}$ & $\begin{array}{c}\text { Severe/ } \\
\text { Infarct }(>13)\end{array}$ & Total \\
\hline \multirow{3}{*}{\multicolumn{2}{|c|}{ SYNTAX Risk Category }} & & & $52(38.8 \%)$ & $8(6.0 \%)$ & $17(12.7 \%)$ & $40(29.8 \%)$ & $117(87.3 \%)$ \\
\hline & & Interme & $(>22)$ & I (0.7\%) & I (0.7\%) & $2(1.5 \%)$ & $13(9.8 \%)$ & $17(12.7 \%)$ \\
\hline & & & & $53(39.5 \%)$ & $9(6.7 \%)$ & $19(14.2 \%)$ & $53(39.6 \%)$ & $134(100 \%)$ \\
\hline \multicolumn{9}{|c|}{ Stratification of SYNTAX scores } \\
\hline \multicolumn{9}{|c|}{ Correlation between stratified SYNTAX scores on angiography and SDS on myocardial perfusion } \\
\hline Strata & & & & $\mathrm{N}$ & SDS & $\begin{array}{l}\text { SYNTAX } \\
\text { Score }\end{array}$ & $\begin{array}{c}\text { Spearman's } \\
\text { Correlation } \\
\text { Coefficient } \\
\text { (rs) }\end{array}$ & P-value \\
\hline SYNTAX $<$ & & & & 117 & Total SDS & $\begin{array}{c}\text { Total } \\
\text { SYNTAX } \\
\text { score }\end{array}$ & 0.034 & 0.718 \\
\hline SYNTAX & & Inte & high & 17 & Total SDS & $\begin{array}{c}\text { Total } \\
\text { SYNTAX } \\
\text { score }\end{array}$ & -0.165 & 0.528 \\
\hline
\end{tabular}

territory, or have diffuse disease throughout the epicardial coronary vasculature resulting in a global ("balanced") ischaemia. Such "balanced ischaemia" may not be detectable on sestaMIBI because stress induced hypo-perfusion with Tc99 sestaMIBI scans depend on relative differences in regional myocardial perfusion. ${ }^{(9)}$ The 39 patients with normal angiograms and abnor- mal myocardial perfusion may have been the consequence of other conditions such as microvascular dysfunction, hypertensive heart disease or hypertrophic cardiomyopathy. These observed mismatches have been explored in this study using SDS and SYNTAX scores to assess the relationship between the coronary artery distribution on angiography and myocardial perfusion on sestaMIBI. 


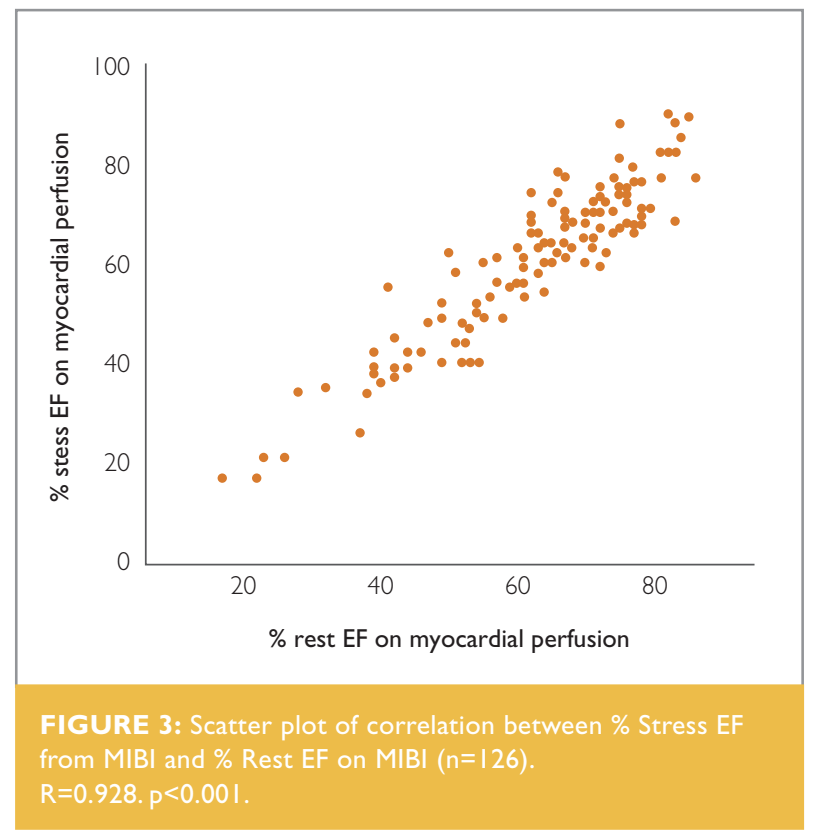

The SYNTAX score evaluates anatomy on coronary angiography and categorises risk into low (score $\leq 22$ ), intermediate (score 23 - 32), and a high (score $\geq 33$ ). The SDS evaluates myocardial perfusion on sestaMIBI and categorises ischaemic burden into normal, mild, moderate and severe. In our study, total SYNTAX scores and total SDS had a weak positive correlation $(p=0.015)$. In a stratified comparison of SDS and SYNTAX score Tanaka found significant correlations predominantly amongst patients with a low risk. Interestingly, however, such correlation was absent amongst patients with intermediate-high risk. ${ }^{(7)}$ Our results from the split strata are similar to Tanaka because the correlation in the low risk group disappeared in each stratum and became slightly negative in the intermediate-high risk group.

Ortiz-Pérez evaluated correspondence between culprit vessel on angiography (instead of using the SYNTAX score) and regional perfusion defects on 17 segment myocardial perfusion using cardiovascular magnetic resonance. Their study participants presented with first ST elevation myocardial infarction for primary percutaneous intervention to the culprit vessel. Results showed that 4 of the 17 segments were completely specific for LAD occlusion but no segment could be exclusively attributed to the circumflex or RCA occlusion. ${ }^{(10)}$ Similarly, exploring regional myocardial blood flow in our study using SYNTAX scores and SDS, showed LAD had slight positive correlation, circumflex and RCA had no evidence of correlation.

The SYNTAX scoring system is based on the severity of luminal diameter narrowing and weighed according to the usual blood flow to the left ventricle in each vessel or vessel segment.
Proximal and mid LAD weighting factors were 3.5 and 2.5, respectively, for both the left and right dominant systems. These were higher than the RCA weighting factor which was I for right system and 0 for left, and circumflex weighting factors which was I for right system and 1.5 for left.(8) The SYNTAX score accounted for regional myocardial blood flow differences, but the SDS does not account for this. This study reflected the differences in regional SYNTAX scores for LAD compared to RCA and circumflex.

The SYNTAX score accounts for both left and right systems and for varying numbers of perforating vessels and branches derived from the LAD, circumflex and RCA. ${ }^{(8)}$ The SDS scoring system, however, uses 17 segments that are all orientated to the right dominance system only. ${ }^{(6)}$ In our study, only 103 (76\%) participants had right sided dominance.

The contribution of each coronary segment to the LV blood flow is used as a multiplication factor for the calculation of the SYNTAX score. However, according to the SYNTAX score, only a lesion with $50 \%$ minimum reduction in luminal diameter by visual assessment was significant. Less severe lesions were therefore excluded in the SYNTAX score, ${ }^{(8)}$ irrespective of the assigned weighting factor of the vessel.

In our study, converse to the findings when scores were split into strata, the coronary risk categories and ischaemic burden category were significant with low risk (having no ischaemia) and the intermediate-high risk (having severe ischaemia) $(p=0.001)$.

A study by Galik in 1995 assessed myocardial perfusion simultaneously with left ventricular function on angiography during transient coronary occlusion. Significant correlation was noted between total perfusion defect size and overall left ventricular ejection fraction during occlusion. However there was a substantial individual variation in changes to myocardial perfusion and ventricular function during acute coronary occlusion by a single culprit vessel. Impairment of left ventricular function was disproportionately more severe during proximal or mid LAD occlusion and was accompanied by very large, reversible perfusion defects. Intermediate effects were seen during left circumflex artery occlusion. Interestingly, no significant changes in left ventricular function occurred during RCA occlusion.(11) In the SYNTAX score, proximal and mid LAD were given higher weighting factors than distal LAD, circumflex or RCA. This weighted factor on the SYNTAX score appeared to reflect in ventricular function on angiography and the perfusion defects on myocardial perfusion noted in Galik's study. This would suggest that there is correspondence in overall LV function between angiography and myocardial perfusion, although regional flow differences may exist. In our study there 
was high correlation between \%EF for (rest and stress) perfusion and the categories of LVF on angiography. There was inability to detect the regional blood flow limitations.

\section{LIMITATIONS TO THE STUDY}

Myocardial perfusion is an assessment tool to determine indications for angiography in patients without typical angina. Our study consisted of patients who did not have typical angina; they were also considered to be medium to lower risk for CAD, a safer group to undergo stress testing. Stress testing carries the risk of a cardiac event in high risk patients with angina induced by little effort. Therefore a body of patients who may have angina (especially on minimal effort) are excluded.

For adequate stress on myocardial perfusion testing, $80 \%$ target heart rate must be reached on stress test to accurately compare with rest studies. Patients who may not reach THR, from causes such as poor effort tolerance, claudication, were excluded.

\section{CONCLUSION}

Our study concurred with previous studies because there was an overall weak positive correlation between total SYNTAX score and total SDS and stratification of data into 2 layers (low risk and intermediate-high risk) demonstrated that the correlation observed in low risk disappeared at higher scores, and became slightly negative. In regional distribution, the LAD reflected the weighting factors in the design of the SYNTAX score. Correlation of regional SYNTAX score and SDS, showed LAD had very slight positive correlation, circumflex and RCA had no correlation. However, the \%EF on myocardial perfusion corresponded with the categories of LV function visually observed at angiography. Converse to the findings for scores, the categories (coronary risk and ischaemic burden) were associated with low risk (having no ischaemia) and intermediatehigh risk (having severe ischaemia).

We therefore conclude that the inherent design of the scoring systems may explain the observed differences. Compared to SDS, SYNTAX score accounted for both left and right dominant systems, had a weighting factor that accommodated the differences in flow distribution, and defined a lesion with 50\% stenosis as significant. This study highlights the need to consider the regional myocardial blood flow limitations in perfusion studies, and to account for variations in each patient's anatomy when screening for angiography.

Suggestions going forward: The SYNTAX score gives a 12-month predictive value for major adverse coronary event rates for the risk categories and the decision to intervene with $\mathrm{PCl}$ or CABG. This is a suggested follow-up study to perform on the cohort.

\section{ACKNOWLEDGEMENTS}

Prof Mariam Adhikari

Professor of Cardiology at Nelson R Mandela School of Medicine University at University of KwaZulu-Natal; and Coronary Care Unit RK Khan Hospital, Durban.

\section{Prof Datshana Prakash Naidoo}

Professor of Cardiology at Nelson R Mandela School of Medicine KwaZulu-Natal and Coronary Care Inkosi Albert Luthuli Central Hospital, Durban.

\section{Mr Bertus Olefse}

Nuclear Physicist, Department of Nuclear Medicine, Inkosi Albert Luthuli Central Hospital, Durban.

\section{Conflict of interest: none declared.}

\section{REFERENCES}

I. Karnath B, Holden MD, Hussain N. Chest Pain: Differentiating cardiac from noncardiac causes. Hospital Physician. 2004;38:24-7.

2. Serruys PW, Morice M, Kappetein AP, et al. Percutaneous coronary intervention versus coronary-artery bypass grafting for severe coronary artery disease. N Engl J Med. 2009;360(10):961-72.

3. Serruys PW, Onuma $Y$, Garg $\mathrm{S}$, et al. Assessment of the SYNTAX score in the STNTAX study. Eurolntervention. 2009;5:50-6.

4. Holly TA, Abbott BG, Al-Mallah M, et al. ASNC imaging guidelines for nuclear cardiology procedures: Single photon-emission computed tomography. Journal of Nuclear Cardiology 20 I 0; 107 I (358I).

5. Kakhki VD, Sadeghi R, Torabian-Kakhki M, et al. Semi-quantitative segmental perfusion scoring in myocardial perfusion SPECT: Visual vs. automated analysis. Iran J Nucl Med. 2014;22(2)(Serial No 42).

6. Cerqueira MD, Weissman NJ, Dilsizian V, et al. Standardised myocardial segmentation and nomenclature for tomographic imaging of the heart a statement for healthcare professionals from the cardiac imaging committee of the council on clinical cardiology of the American Heart Association. Circulation. 2002; 1 05:539-542.

7. Tanaka H, Chikamori T, Hida S, et al. The relation of SYNTAX score with myocardial ischaemia as assessed on myocardial perfusion imaging. Circulation Journal. 2013;77:2772-7.

8. Sianos G, Morel M, Kappetein AP, et al. The SYNTAX Score: An angiographic tool grading the complexity of coronary artery disease. Eurolnterv. 2005; 1:219-227.

9. Lesser JR, Bae R, Flygenring B, et al. Balanced myocardial ischaemia: A case of "normal" stress Tc99 sestamibi scan and diagnosis. Heart, 2005;9I (7):p.e53

10. Ortiz-Pérez JT, Rodriguez J, Meyers SN, et al. Correspondence between the 17-Segment model and coronary arterial anatomy using contrastenhanced cardiac magnetic resonance imaging. JACC: Cardiovascular imaging. 2008; I (3).

II. Gallik DM, Obermueller SD, Swarna US, et al. Simultaneous assessment of myocardial perfusion and left ventricular function during transient coronary occlusion. J Am Coll Cardiol 1995;25: I529-38. 